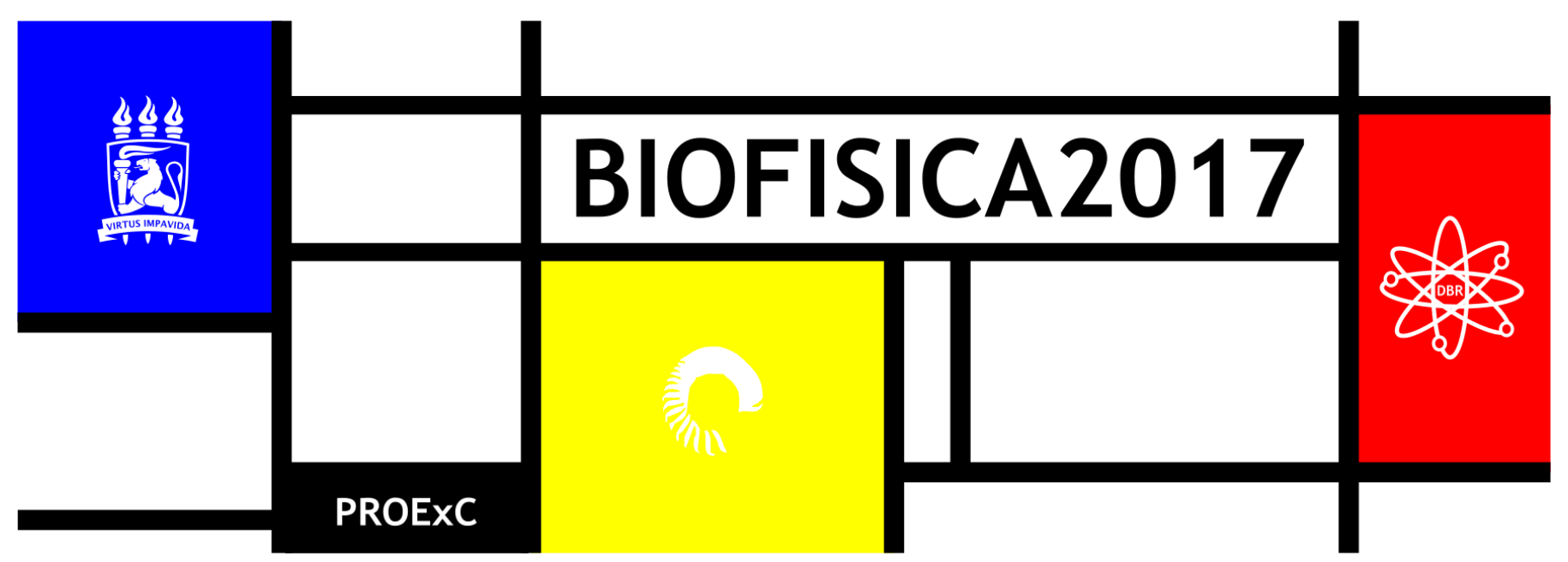

\title{
COMPARAÇÃO MORFOLÓGICA DA CÉLULA ESPERMÁTICA EQUINA NO SÊMEN FRESCO E REFRIGERADO
}

\author{
Lenilda Teixeira da Silva ${ }^{1 *}$, Marciane da Silva Maia², José Joussier Maia de Aquino ${ }^{3}$, Carlos Eduardo Bezerra de \\ Moura $^{4}$
}

${ }^{1}$ Bióloga Autônoma, ${ }^{2}$ Embrapa/EMPARN, ${ }^{3}$ Médico Veterinário Autônomo, ${ }^{4}$ UFERSA *bio_leny@yahoo.com.br

\section{INTRODUÇÃO}

No Brasil, os sistemas de refrigeração de sêmen equino mais utilizados são os sistemas passivos, no qual, o abaixamento da temperatura do sêmen é mantido em caixas isotérmicas próximas a uma fonte de frio (gelo biológico reciclável), que segundo o sistema deixará o sêmen resfriado a 15 a $20^{\circ} \mathrm{C}$, ou refrigerado a 4 a $6^{\circ} \mathrm{C}$, para preservação e transporte do material biológico em períodos variando de 1 a 48 horas. De modo geral, o sêmen mantido a $5^{\circ} \mathrm{C}$, pode ser utilizado por até 48 horas. Essas caixas isotérmicas deverão apresentar certas condições adequadas, como principalmente: completo isolamento do ambiente; ter baixo custo; ser inócuo para os espermatozóides; manutenção da temperatura para o tempo proposto; ser possível realização de curva de resfriamento lento; entre outras situações adversas (CANISSO et al., 2008).

De acordo com Moran et al. (1992), no resfriamento do sêmen de $37^{\circ} \mathrm{C}$ a $5^{\circ} \mathrm{C}$, a taxa de refrigeração deve ser controlada, especialmente entre $19^{\circ} \mathrm{C}$ e $8^{\circ} \mathrm{C}$, pois é a faixa de maior sensibilidade da célula espermática equina, já que neste intervalo pode ocorrer o choque térmico. Destacando-se que nesta faixa de temperatura, os lipídeos da membrana plasmática estão passando pela fase de transição, que corresponde do estado fluido para o gel; e após sair dessa faixa, o resfriamento pode ser feito de forma rápida a partir de $8^{\circ} \mathrm{C}$ até $5^{\circ} \mathrm{C}$.

Segundo Squires et al. (1999) citado por Nunes, Zúccari e Costa e Silva (2006), o metabolismo dos espermatozóides é alto, e a cada redução de $10^{\circ} \mathrm{C}$, provoca a queda de aproximadamente $50 \%$ do metabolismo. Quando os espermatozóides são mantidos a $5^{\circ} \mathrm{C}$, somente $10 \%$ de seu metabolismo são necessários para que as células se mantenham viáveis.

Na preservação espermática pela refrigeração, existem fatores que afetam a qualidade do sêmen equino refrigerado, devido às lesões celulares induzidas pelo frio, e as membranas espermáticas são as estruturas mais afetadas pelo choque térmico, podendo acarretar mudanças na sua permeabilidade, que provocará alterações funcionais e metabólicas, consequentemente prejudicando a motilidade e a capacidade fecundante dos espermatozóides. Destacando que, o resfriamento pode induzir ruptura acrossomal e isso acarreta a uma redução da fertilidade (NUNES, ZÚCCARI e COSTA e SILVA, 2006).

A refrigeração do sêmen, que é uma biotécnica voltada para a reprodução, tem como finalidade aumentar o período de estocagem do sêmen, favorecendo o seu transporte, ou seja, permitindo o envio da dose inseminante para locais distantes. No entanto, o sucesso no uso do sêmen refrigerado resultará da preservação dos espermatozoides durante o tempo do transporte, sem que ocorra a perda de sua capacidade fecundante; assim os métodos de resfriamento tem permitido prolongar a viabilidade dos espermatozóides por períodos de até 48hs para equinos, mantendo-se a temperatura mínima de $5^{\circ} \mathrm{C}$ (SILVA FILHO et al., 1998; VALE FILHO; VALLE; NASCIMENTO, 2011).

Entretanto, a avaliação isolada da morfologia espermática pode não afirmar que o potencial de fertilidade de um ejaculado é alto, mas pode indicar se o potencial de fertilidade é baixo, 
principalmente quando houver altas porcentagens de anormalidades espermáticas (BRITO, 2007).

Além disso, uma inspeção morfológica criteriosa fornece informações adicionais sobre as características individuais dos espermatozóides, e este dado é importante porque o sêmen pode possuir boa motilidade dos espermatozóides, e ainda ter uma incidência relativamente alta de anormalidades morfológicas dos espermatozóides. Como também, os garanhões podem ter muitas anormalidades espermáticas e ainda apresentar fertilidade normal (VARNER, 2008).

O objetivo deste trabalho foi comparar a morfopatologia dos espermatozóides do sêmen fresco com o refrigerado de garanhões da raça Pônei Brasileiro (Equus caballus), sob condições de clima e manejo do Agreste potiguar (RN), região nordeste do Brasil.

\section{MATERIAIS E MÉTODOS}

A coleta do sêmen foi realizada no Haras Orlando Monteiro, localizado no município de Santa Maria - RN, situado na mesorregião Agreste Potiguar.

As análises subsequentes do sêmen fresco e refrigerado foram efetuadas no Laboratório do Departamento de Morfologia da Universidade Federal do Rio Grande do Norte (UFRN), localizado no Campus central Natal - RN e, no Laboratório de Reprodução Animal da Empresa de Pesquisa Agropecuária do Rio Grande do Norte (EMPARN), situada no município de Parnamirim - RN.

Foram utilizados uma fêmea em estro e cinco garanhões adultos com 5 a 18 anos de idade, clinicamente sadios e em bom estado nutricional da raça Pônei Brasileiro. Todos os animais foram mantidos sob as mesmas condições de manejo, sendo alojados em baias individuais no Haras e alimentados com pastagem nativa, feno, concentrado, sal mineral e água ad libitum.

O sêmen foi colhido semanalmente, no período de março a abril de 2012, perfazendo um total de cinco dias de coleta. As coletas foram efetuadas no período da manhã, e em cada dia era coletado um ejaculado de cada garanhão. Os ejaculados foram colhidos por meio de vagina artificial aquecida à temperatura de 41 a $42^{\circ} \mathrm{C}$ e com o auxílio de uma fêmea em estro para a estimulação do macho.

Logo após a coleta, o ejaculado era filtrado para separação da fração gelatinosa e da fração rica em espermatozoides. Em seguida era submetido à avaliação das características macro e microscópicas do sêmen.

Em seguida, uma alíquota de sêmen $(3 \mathrm{ml})$ de cada garanhão era colocada em tubo PVC de $15 \mathrm{ml}$ e diluída na proporção 1:1 (3 ml de diluente: $3 \mathrm{ml}$ de sêmen) com 0 diluente comercial BotuSêmen ${ }^{\circledR}$ (contendo na sua composição leite em pó desnatado e antibióticos). A seguir, o sêmen era fracionado em 3 alíquotas, as quais eram acondicionadas em microtubos e mantidas na caixa isotérmica BotuFlex® (Botupharma) contendo blocos de gelo para serem refrigeradas por 24 horas. Após o acondicionamento, as amostras eram transportadas aos laboratórios da UFRN e EMPARN, para a finalização das avaliações.

As análises de morfologia foi realizada nos seguintes momentos: fresco e após $24 \mathrm{~h}$ de refrigeração.

$\mathrm{Na}$ avaliação da morfologia espermática, foi realizada nas amostras de sêmen fixadas em solução formol-salina e submetidas à técnica de preparação úmida. Uma pequena gota de sêmen era colocada sobre uma lâmina e coberta com lamínula, em seguida, retirava-se o excesso de líquido das bordas com auxílio de um papel-filtro após ligeira pressão central da lamínula (VALE FILHO; VALLE; NASCIMENTO, 2011). Para a avaliação, a lâmina era levada ao microscópio de contraste de fase (Leica, DM 750), em um aumento de 1000x sob imersão e com o auxílio de um contador de células digital.

As células foram classificadas em normais e anormais. As anomalias espermáticas foram classificadas em defeitos maiores e defeitos menores conforme o modelo proposto por Blom 1973. A contagem das alterações morfológicas foi realizada em 200 células, contando-se células normais e apenas um defeito por célula anormal. Quando observados dois ou mais defeitos na mesma célula, registrou-se em ordem de prioridade, o defeito maior em relação ao menor e, se observados dois defeitos de mesma classificação, registra-se apenas o de maior frequência/incidência (FRENEAU, 2011). Os valores foram expressos em porcentagem. Para interpretação dos resultados foram consideradas as recomendações para sêmen de equino do Colégio Brasileiro de Reprodução Animal (CBRA, 1998).

$O$ delineamento experimental utilizado foi o inteiramente casualizado em esquema fatorial, com cinco animais, cinco ejaculados por animal e dois momentos de avaliação ( 0 = sêmen fresco e 24 = refrigerado) perfazendo um $N=50$. 0 efeito do animal e do momento sobre a morfologia espermática foi avaliado utilizando-se a análise de variância (ANOVA) em esquema fatorial. Para a comparação das médias utilizou-se o teste de Duncan a $95 \%$ de confiança. Todas as análises foram realizadas com o auxílio do programa estatístico Statgraphics (Satatistical Graphis Corp., USA).

\section{RESULTADOS E DISCUSSÃO}

$\mathrm{Na}$ avaliação da morfologia espermática do sêmen fresco, o percentual do total de defeitos espermáticos no sêmen fresco encontrados nos garanhões pôneis do Rio Grande do Norte foi $36,08 \pm 9,67 \%$, o de defeitos maiores foi de $25,5 \pm 7,65 \%$ e os defeitos menores foi $10,58 \pm 4,43 \%$ (Tabela 1 ). Os valores obtidos no total de defeitos, nos defeitos maiores e nos defeitos menores foram semelhantes aos obtidos por Araújo e Araújo (2011) em pôneis da raça Brasileira no Rio de Janeiro. Já o valor total de formas anormais no estudo de Neves et al. (2006) também em garanhões da raça Brasileira sendo que criados no Rio Grande do Sul foi inferior ao observado em nosso estudo. No entanto, os pôneis do Rio Grande do Sul foram os que apresentaram o menor valor de defeitos espermáticos (32,6\%), e os pôneis do Rio de Janeiro foram os que mostraram o maior 
valor do total de defeitos $(37,12 \%)$, em comparação das três localizações.

Dentre os defeitos maiores, o percentual total de gota citoplasmática proximal (7\%) e da cauda fortemente dobrada/enrolada (3,7\%) diferiu dos obtidos por Araújo e Araújo (2011), apresentando uma maior e uma menor percentagem, respectivamente. Porém, as patologias de peça intermediária (4\%) foram semelhantes. Já dentre os defeitos menores, o percentual total de gota citoplasmática distal $(2,92 \%)$ e de cauda enrolada ou dobrada (3,34\%) foram semelhantes ao estudo de Araújo e Araújo (2011). O alto percentual de gota citoplasmática proximal observado nesse estudo pode ser devido ao longo período de repouso sexual, em que os garanhões encontravam-se antes do início do experimento.

Conforme o Colégio Brasileiro de Reprodução Animal (1998), o percentual de espermatozóides anormais no ejaculado não deve ultrapassar $30 \%$ na espécie equina. Sendo assim, os animais do nosso estudo encontram-se no limiar do valor considerado normal para a espécie equina. No entanto, a idade dos animais, o repouso sexual prévio, assim como a alta consanguinidade observada na raça Pônei Brasileira, podem ter influenciado os resultados deste estudo, culminando em percentual elevado de patologias espermáticas no sêmen fresco.

Segundo Alvarenga e Papa (2009) no garanhão, o fator idade associado a não inclusão do critério de fertilidade na seleção de reprodutores, leva ao aumento da incidência de problemas relacionados à espermatogênese. Além disso, deve-se a pouca variabilidade genética desta raça, pois os criadores de pôneis da raça Brasileira utilizam preferencialmente os reprodutores com os melhores padrões zootécnicos, assim, aquele garanhão com bons quesitos de morfologia tende a ser o mais utilizado como reprodutor. Porém, de acordo com Bergmann et al. (1997), a endogamia pode ser atrativa em relação ao interesse zootécnico dos animais, mas causa efeitos adversos sobre a reprodução. Todos esses fatores podem ter contribuído para o elevado percentual de patologias espermáticas observado no sêmen fresco dos animais neste estudo.

$\mathrm{Na}$ avaliação da morfologia espermática do sêmen refrigerado, o total de defeitos espermáticos no sêmen refrigerado foi $42,84 \pm$ $7,79 \%$, o de defeitos maiores foi de $28,46 \pm 5,47 \%$ e os defeitos menores foi $14,38 \pm 4,89 \%$ (Tabela 1 ).

Conforme o Colégio Brasileiro de Reprodução Animal (1998), as anormalidades espermáticas para sêmen resfriado não podem ultrapassar $40 \%$ de defeitos totais e $20 \%$ de defeitos maiores. Assim, os resultados obtidos estão fora do padrão considerado normal para espécie.

Comparando as anomalias espermáticas no sêmen fresco com o sêmen refrigerado, observou-se que o processo de refrigeração teve efeito deletério sobre a morfologia espermática. 0 total de defeitos espermáticos, assim como o total de defeitos maiores (DEMA) e de defeitos menores (DEME) foi significativamente maior $(P<0,05)$ no sêmen refrigerado que no sêmen fresco (Tabela 1). Os defeitos morfológicos dos espermatozóides podem ser visualizados nas figuras 1 e 2 .
Observou-se um aumento significativo $(\mathrm{P}<0,05)$ no percentual de células com alterações acrossomais e de cauda no sêmen refrigerado comparado ao sêmen fresco. Possivelmente, esse aumento se deva ao efeito do choque de temperatura sofrido pelos espermatozóides durante a refrigeração (NUNES et al., 2006; CANISSO et al., 2008).

Tabela 1. Morfologia espermática (média $\pm d p$ ) do sêmen de garanhões pônei refrigerado por 24 horas comparado ao sêmen fresco (0 horas).



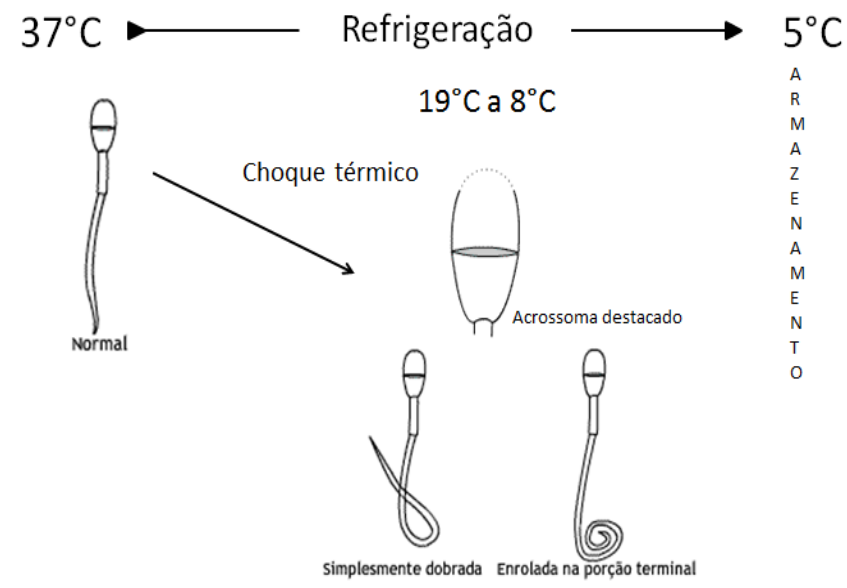

Figura 1. Esquema representativo dos danos morfológicos causados pelo resfriamento (Fonte: UFRGS (2012) - Adaptado). 


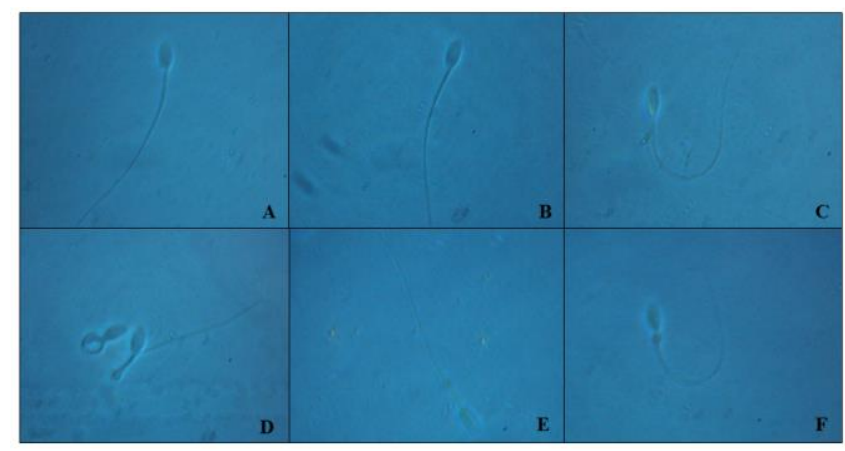

Figura 2. Microscopia de contraste de fase de espermatozoides de garanhões pôneis da raça Brasileira após fixação em solução formol-salina: A - espermatozoide com morfologia normal; B - espermatozoide normal com nítida inserção abaxial comum dos equinos; C - espermatozoide com cauda dobrada; D - espermatozoides com cauda fortemente enrolada e cauda fortemente dobrada (esquerda p/ direita, respectivamente); E - espermatozoide com gota citoplasmática distal; F espermatozoide com duas patologias: gota citoplasmática proximal e cauda dobrada. 100x.

\section{CONCLUSÕES}

A maioria dos garanhões demonstrou uma média de patologia espermática compatível com a espécie equina, no entanto, o percentual médio das anormalidades espermáticas no sêmen fresco e refrigerado foram superiores ao percentual preconizado pelo Colégio Brasileiro de Reprodução animal (1998) de sêmen equino para efeito de comercialização. Na comparação da morfopatologia nos dois momentos avaliados, o processo de refrigeração induziu principalmente alterações no acrossoma e na cauda dos espermatozóides. Observou-se também que a motilidade espermática no sêmen refrigerado foi afetada pelo percentual de defeitos menores. No entanto, este aumento de patologias não foi impactante considerando as outras características seminais, concluindo-se que os garanhões pôneis da raça Brasileira criados nas condições de clima e manejo do Agreste Potiguar apresentaram-se aptos para desempenhar suas atividades reprodutivas.

\section{REFERÊNCIAS}

ALVARENGA, M. A.; PAPA, F. O. Principais distúrbios reprodutivos observados em garanhões no Brasil. Revista Brasileira Reprodução Animal, Belo Horizonte, n. 6, p. 204-209, dez. 2009. Suplemento.

ARAÚJO, A. M. S.; ARAÚJO, S. A. C. Patologias espermáticas mais comuns em garanhões da raça Pônei Brasileiro. Archivos de Zootecnia, v. 60, n. 229, p. 145-148, 2011.

BERGMANN, J. A. G.; COSTA, M. D.; MOURÃO, G. B.; HOURI NETO, M. Efeito da endogamia sobre características morfológicas em pôneis da raça Brasileira. Arquivo Brasileiro de Medicina Veterinária e Zootecnia, v. 49, n. 1, p. 103-111, 1997. BRITO, L. F. C. Evaluation of Stallion Sperm Morphology. Clinical Techniques in Equine Practice, v. 6, p. 249-264, 2007.

CANISSO, I. F.; SOUZA, F. A.; SILVA, E. C.; CARVALHO, G. R.; GUIMARÃES, J. D.; LIMA, A. L. Alguns aspectos fundamentais do exame clínico andrológico de jumentos (Equus asinus). Revista
Brasileira Reprodução Animal, Belo Horizonte, v. 32, n. 4, p. 233-239, out/dez. 2008.

COLÉGIO BRASILEIRO DE REPRODUÇÃO ANIMAL. Manual para exame andrológico e avaliação de sêmen animal. Belo Horizonte: CBRA, 1998.

FRENEAU, G. E. Aspectos da morfologia espermática em touros. Revista Brasileira Reprodução Animal, Belo Horizonte, v. 35, n. 2, p. 160-170, abr/jun. 2011.

MORAN, D. M.; JASKO, D. J.; SQUIRES, E. L.; AMANN, R. P. Determination of temperature and cooling rate which induce cold shock in stallion spermatozoa. Theriogenology, v. 38, p. 999-1012, 1992.

NEVES, A. P.; BUSTAMANTE-FILHO, I. C.; TREIN, C. R.; MALSCHITZKY, E.; JOBIM, M. I. M.; MATTOS, R. C. Abstract: Reproductive parameters and sperm freezability of stallions of the Brazilian pony breed. Animal Reproduction Science, v. 94, p. 67-69, 2006.

NUNES, D. B.; ZÚCCARI, C. E. S. N; COSTA e SILVA, E. V. D. Fatores relacionados ao sucesso da inseminação artificial de éguas com sêmen refrigerado. Revista Brasileira Reprodução Animal, Belo Horizonte, v. 30, n. 1/2, p. 42-56, jan/jun. 2006. SILVA FILHO, J. M.; FONSECA, F. A.; PALHARES, M. S.; WANDERLEY, A. T.; OLIVEIRA, H. N. Avaliação de uma Técnica de Diluição e Transporte de Sêmen Eqüino, para as Condições Brasileiras. Revista Brasileira de Zootecnia, v. 27, n. 1, p. 6674, 1998.

UNIVERSIDADE FEDERAL DO RIO GRANDE DO SUL. Reprodução Animal - Célula espermática. Disponível em:<http://penta3.ufrgs.br/veterinaria/index.html>. Acesso em: 5 de fev. 2017.

VALE FILHO, R. D. V.; VALLE, G. R.; NASCIMENTO, E. F. Patologia Espermática. In: NASCIMENTO, E. F.; SANTOS, R. L. (Ed.). Patologia da Reprodução dos Animais Domésticos. 3. ed. Guanabara Koogan, 2011. cap. 13, p. 129-149.

VARNER, D. D. Developments in stallion semen evaluation. Theriogenology, v. 70, p. 448-462, 2008. 